\title{
Latin American Consensus on management of residual cardiometabolic risk. A consensus paper prepared by the Latin American Academy for the Study of Lipids and Cardiometabolic Risk (ALALIP) endorsed by the Inter-American Society of Cardiology (IASC), the International Atherosclerosis Society (IAS), and the Pan-American College of Endothelium (PACE)
}

Consenso latinoamericano para el manejo del riesgo residual cardiometabólico. Consenso realizado por la Academia Latinoamericana de Lipidología y Riesgo Cardiometabólico (ALALIP), con el aval de la Sociedad Interamericana de Cardiología (SIAC), la Sociedad Interamericana de Aterosclerosis (IAS) y el Colegio Panamericano de Endotelio (PACE)

Carlos I. Ponte-Negretti ${ }^{1 *}$, Fernando S. Wyss' ${ }^{2}$, Daniel Piskorz ${ }^{3}$, Raul D Santos ${ }^{4}$, Raul Villar ${ }^{5}$, Alberto Lorenzattí, Patricio López-Jaramillo ${ }^{7}$, Peter P. Toth ${ }^{8}$, A. Juan J. Amaro ${ }^{9}$, Alfonso K. Rodrigo ${ }^{10}$, Fernando Lanas ${ }^{11}$, Miguel Urina-Triana ${ }^{12}$, Jofre Lara ${ }^{13}$, T. Osiris Valdés ${ }^{14}$, José R. Gomez-Mancebo ${ }^{15}$, Alfonso Bryce ${ }^{16}$, Leonardo Cobos S. ${ }^{17}$, Adriana Puente-Barragan ${ }^{18}$, Vladimir E. Ullauri-Solórzano ${ }^{19}$, Felix A. Medina-Palomino ${ }^{20}$, Alfredo F. Lozada ${ }^{21}$, Maritza Duran²2, Percy Berrospi23, David Miranda24, Juan J. Badimon²5, J. José R. González²6, and Peter Libby²7

${ }^{1}$ Unit of Cardiometabolic Medicine, La Floresta Medical Institute, Caracas, Venezuela; ${ }^{2}$ Services and Cardiovascular Technology of Guatemala CARDIOSOLUTIONS, Guatemala, Guatemala; ${ }^{3}$ Institute of Cardiology Sanatorio Británico SRL Rosario, Argentina; ${ }^{4}$ Lipid Clinic Heart Institute (InCor) University of Sao Paulo Medical School Hospital, Sao Paulo, Brazil; ${ }^{5}$ Integra Médica, La Serena, Chile; ${ }^{6}$ Department of Cardiology, Hospital Instituto Médico DAMIC/Rusculleda Foundation for Research in Medicine, Cordoba Argentina; ${ }^{7}$ Integral Center for the Prevention of Cardiometabolic Diseases (CIPCA) and Instituto Masira, UDES, Bucaramanga, Colombia; ${ }^{8}$ University of Illinois College of Medicine, Peoria, Illinois, Michigan State, USA; ${ }^{9} \mathrm{Clinica}$ Santa Sofía, Caracas, Venezuela; ${ }^{10}$ Advanced Center for Metabolic Medicine and Nutrition, Santiago de Chile, Chile; ${ }^{11}$ University of La Frontera, Temuco, Chile; ${ }^{12}$ Faculty of Health Sciences, Simón Bolívar University, Barranquilla Colombia; ${ }^{13}$ Department of Cardiology, Hospital Solca Guayaquil, Ecuador; ${ }^{14}$ Central Medical Center La Romana, Dominican Republic; ${ }^{15}$ Department of Cardiology, Hospital Universitario de Caracas, Universidad Central de Venezuela, Caracas, Venezuela; ${ }^{16}$ CARDIOGOLF Research Unit, El Golf Clinic, Lima, Peru; ${ }^{17}$ Cardiology Service, Hospital El Pino, Cardiocob Research Unit, Santiago de Chile, Chile; ${ }^{18}$ Centro Médico Nacional 20 de Noviembre (ISSSTE), Mexico City, Mexico; ${ }^{19} \mathrm{Hospital}$ Metropolitano, Quito, Ecuador; ${ }^{20}$ Univeridad Peruana Cayetano, Hospital Nacional Cayetano Heredia, Peru; ${ }^{21}$ Austral University Hospital, Buenos Aires, Argentina; ${ }^{22}$ FISPEVEN (Foundation for Clinical Research in Public and Epidemiological Health in Venezuela), Clínica El Ávila, Caracas, Venezuela; ${ }^{23}$ Cardiology Service, SANNA Clinica El Golf, Lima, Peru; ${ }^{24}$ Clínica San Felipe, Lima, Peru; ${ }^{25}$ Atherothrombosis Research Unit, Cardiovascular Institute, The Mount Sinai School of Medicine, New York, USA; ${ }^{26}$ University Hospital Complex of Santiago de Compostela, Santiago de Compostela, Galicia, Spain; ${ }^{27}$ Division of Cardiovascular Medicine, Department of Medicine, Brigham and Womens' Hospital, Harvard Medical School, Boston, MA, USA

\begin{abstract}
Background: Hypertension, hyperglycemia, dyslipidemia, overweight, obesity, and tobacco (smoking, chewing, and vaping), together with a pro-inflammatory and procoagulant state, are the main risk factors related to atherosclerotic cardiovascular disease. Objective and methods: A group of experts from the Americas, based on their clinical expertise in cardiology, cardiovascular prevention, and cardiometabolic (CM) diseases, joined together to develop these practical recommendations
\end{abstract}

Correspondence:

${ }^{*}$ Carlos I. Ponte-Negretti

E-mail: ciponten@gmail.com license (http://creativecommons.org/licenses/by-nc-nd/4.0/).

Date of reception: 08-01-2021

Date of acceptance: 14-05-2021

DOI: 10.24875/ACM.21000005
Available online: $28-06-2021$

Arch Cardiol Mex (Eng). 2022;92(1):99-112

www.archivoscardiologia.com 
for the optimal evaluation and treatment of residual CM risk factors in Latin America, using a modified Delphi methodology (details in electronic TSI) to generate a comprehensive CM risk reduction guideline, and through personalized medicine and patient-centered decision, considering the cost-benefit ratio The process was well defined to avoid conflicts of interest that could bias the discussion and recommendations. Results: Residual risk reduction should consider therapeutic options adapted to specific patient needs, based on five treatment objectives: triglyceride-rich lipoproteins, inflammation, impaired glucose metabolism, high blood pressure, and prothrombotic status. Comprehensive control of all CM risk factors should be a priority to deal with this important public health problem and prevent premature deaths. The recommendations in this paper address the evidence-based treatment of CM risk and are intended for clinical application in Latin American countries.

Keywords: Residual risk. Cardiovascular risk. Cardiometabolic risk factors. Atherosclerotic cardiovascular disease. Inflammation. Thrombosis.

\section{Resumen}

Antecedentes: Un grupo de factores de riesgo cardiometabólicos (hipertensión, hiperglucemia, dislipidemia, sobrepeso, obesidad y tabaco (fumado, masticado, vaporizado), junto con un estado proinflamatorio y procoagulante, son los principales factores de riesgo relacionados con la enfermedad cardiovascular aterosclerótica. Objetivo y métodos: Basándose en su experiencia en cardiología, prevención cardiovascular y enfermedades cardiometabólicas, un grupo de expertos de las Américas se unió para desarrollar estas recomendaciones prácticas para la evaluación y tratamiento óptimos de los factores de riesgo cardiometabólicos residuales en América Latina, utilizando una metodología Delphi modificada con el objetivo de generar una guía integral de pautas para la reducción del riesgo cardiometabólico, mediante la medicina personalizada y la decisión centrada en el paciente teniendo en cuenta la relación costo-beneficio. El proceso fue bien definido para evitar conflictos de intereses que podrían sesgar la discusión y las recomendaciones. Resultados: La reducción del riesgo residual debe considerar opciones terapéuticas adaptadas a las necesidades específicas del paciente, basadas en 5 objetivos de tratamiento: lipoproteínas ricas en triglicéridos inflamación, metabolismo de la glucosa, presión arterial alta y estado protrombótico. El Control integral de todos los factores de riesgo cardiometabólicos debe ser una prioridad para hacer frente a este importante problema de salud pública y prevenir las muertes prematuras. Las recomendaciones de este documento abordan el tratamiento basado en evidencia del riesgo cardiometabólico y están destinadas a la aplicación clínica en los países de América Latina.

Palabras claves: Riesgo residual. Riesgo cardiovascular. Riesgo cardiometabólico. Enfermedad cardiovascular aterosclerótica. Inflamación. Trombosis.

\section{Introduction}

Cardiovascular diseases (CVD) are the primary cause of death and disability in adults around the world 1 . The most frequent form of CVD is atherosclerotic CVD (ASCVD), which is a manifestation of multiple toxic cardiometabolic (CM) risk factors: elevated blood pressure, dysglycemia, dyslipidemia, overweight, obesity, and tobacco usage (smoking, chewing, and vaping). These risk factors induce progressive arterial wall injury by numerous maladaptive responses (endothelial dysfunction, inflammation, prothrombotic, and pro-oxidant state), that begins decades before the occurrence of the first clinical event. Comprehensive CM risk control strategies should optimally treat all CM risk factors.

Based on the foregoing, the ALALIP (Latin American Academy of Lipidology and CM Prevention), together with IASC, IAS, and PCE, convened a group of experts from the Americas, based on their clinical expertise in: cardiology, cardiovascular prevention, and CM diseases, to develop practical recommendations for the optimal evaluation and treatment of $\mathrm{CM}$ risk factors in Latin America. The process was well defined to avoid conflicts of interest that could bias the discussion and recommendations.

We use a modified Delphi methodology aims to generate a comprehensive $\mathrm{CM}$ risk reduction guideline, using personalized medicine and patient-centered decision considering the cost-benefit ratio, based on three premises $^{2,3}$ :

1) Global vision derived from a multidisciplinary expert discussion to incorporate the best scientific evidence.

2) Developing criteria to identify relevant clinical issues.

3) Define practical pathways to improve daily clinical care. 


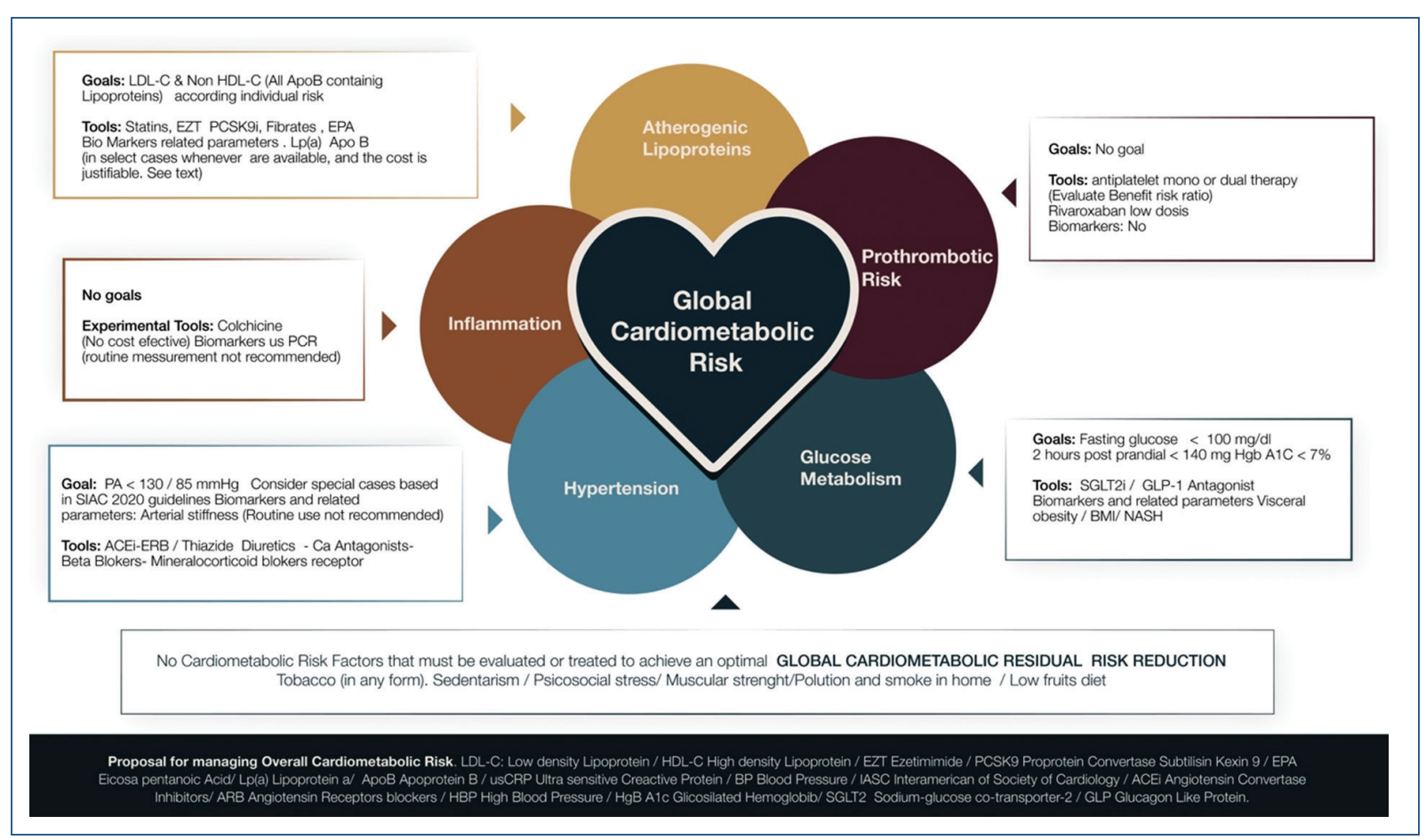

Figure 1. Proposal for managing overall cardiometabolic risk.

In suppl. table 1, we made a detailed description of the document preparation process, the guidelines used for the construction of recommendations and the qualification of evidence.

Residual risk (RR) represents the risk which persists despite reaching the proposed treatment goals for the classic CM risk factors according to the current guidelines ${ }^{4}$. RR applies in primary and secondary prevention scenarios and rises as the individual baseline global risk rises ${ }^{5}$. The concept emerged from the statin trials. Low-density lipoprotein cholesterol (LDL-C) levels are the primary target in patients with dyslipidemia ${ }^{6}$. However, despite reaching LDL-C levels as low as < $70 \mathrm{mg} / \mathrm{dl}$, RR often persists, particularly in higher risk individuals. Originally, RR aimed at identifying and treating atherogenic dyslipidemia (AD): elevated triglyceride (TG), low high-density lipoprotein cholesterol (HDL-C) levels, and a higher proportion of small and dense LDL-C (LDL pattern B) $)^{7,8}$. However, the RR concept should extend beyond $A D$ and apply to all other uncontrolled ASCVD risk factors.

The recommendations by this consensus panel are summarized in figure 1 and table 1 . RR reduction should consider therapeutic options adapted to specific patient needs, based on five treatment objectives:
TG-rich lipoproteins (TgRL), inflammation, impaired glucose metabolism, high blood pressure (HBP), and prothrombotic status. This approach acknowledges various pathophysiological pathways and identifies therapies to consider, with no hierarchical classification, to accomplish an optimal RR reduction, aimed at delivering precise, and personalized medicine ${ }^{9}$. The pharmacotherapy assessed includes: statins, ezetimibe $(E Z T)^{10}$, proprotein convertase subtilisin/kexin 9 inhibitors (PCS$\mathrm{K} 9 \mathrm{i})^{11,12}$, eicosapentaenoic acid (EPA) $)^{13}$, canakinumab ${ }^{14}$, colchicine ${ }^{15-18}$, metformin, sodium-glucose cotransporter 2 inhibitors (SGLT2i) ${ }^{19,20}$, glucagon-like peptide-1 (GLP-1) receptor agonists ${ }^{19,20}$, dual antiplatelet therapy $^{21,22}$, and rivaroxaban ${ }^{23}$.

$\mathrm{CM}$ risk enhancing factors should be assessed routinely, including smoking, physical inactivity, psychosocial stress, inadequate diet, muscle strength, and environmental pollution, which contribute to the risk of CV disease and CV death, in particular, in middle- and low-income countries $^{24}$. CM risk goes beyond the traditional risk factors and, hence, ASCVD prevention involves the proactive evaluation of all of these risk factors.

Based on the above discussion, this consensus recommends a comprehensive assessment of $\mathrm{CM}$ risk (IA). Once the risk factors are identified, treatment should be 
Table 1. Summary of recommendations with level of evidence

\begin{tabular}{|c|c|c|c|}
\hline RECOMMENDATIONS & Class & Level & Ref \\
\hline \multicolumn{4}{|l|}{ CMR assessment and management } \\
\hline $\begin{array}{l}\text { Comprehensive assessment of CMR, including the objectives and their corresponding } \\
\text { therapies, benefit-risk ratio, and cost-effectiveness must be discussed with the patient and } \\
\text { his/her relatives }\end{array}$ & I & A & \\
\hline Optimum treatment should be implemented to achieve the optimal CMR reduction & I & A & \\
\hline
\end{tabular}

\section{LDL-C goals according to risk category}

Low risk: $\mathrm{LDL}-\mathrm{C}<115 \mathrm{mg} / \mathrm{dL} / \mathrm{Non}-\mathrm{HDL}-\mathrm{C}<145 \mathrm{mg} / \mathrm{dL}$

High risk: $\mathrm{LDL}-\mathrm{C}<70 \mathrm{mg} / \mathrm{dL}$ (or at least $50 \%$ reduction)/Non-HDL-C $<100 \mathrm{mg} / \mathrm{dL}$

Very high risk: $\mathrm{LDL}-\mathrm{C}<55 \mathrm{mg} / \mathrm{dL}$ (or at least $50 \%$ reduction)/Non-HDL-C $<85 \mathrm{mg} / \mathrm{dL}$

Atherogenic Dyslipidemia: Non-HDL-C (second therapeutic objective after achieving the primary goal: LDL-C based on risk category)

In patients that, despite receiving statins at adequate doses and being at the right goal according to their risk profile, experience a recurrent atherosclerotic cardiovascular event, their LDL-C goal may be $<40 \mathrm{mg} / \mathrm{dl}$.

\section{Diagnostic strategies}

- Routine calculation of Non-HDL-C (surrogate for ApoB):

- Lp(a) measurement to assess risk.

Indications:

- Premature or progressive ASCVD with maximum lipid-lowering therapy

- Familial hypercholesterolemia

- Premature or progressive ASCVD with maximum lipid-lowering therapy

- Premature ASCVD in family members

- Direct relatives with elevated $L p(a)$

- Failure to achieve expected LDL-C reduction with statin therapy

- Whenever the means are available and the cost is justifiable, $L p(a)$ should be measured

- Measuring $L p(a)$ in patients not included in the above-mentioned cases is not recommended

HDL-C goals or pharmacological therapy not recommended

\section{Therapeutic strategies}

\section{Risk/Clinical Condition/Goa}

Non-pharmacological:

- Nutrition, exercise, weight loss and

smoking cessation

Monotherapy with statins

For every patient, regardless of the risk

As a strategy to help elevate HDL-C

Initial therapy to the lower LDL-C and achieve the goal based on the risk. Select the molecule and dose according to the percentage reduction required to achieve the goal. Use the maximum tolerable dose with no time limit.

Monotherapy with Ezetimibe

Only in case of proven statin intolerance and requiring less than $20 \% \mathrm{LDL}-\mathrm{C}$ reduction

Statins with Fenofibrate

Primary prevention

Secondary prevention

Contraindicated

\begin{tabular}{|l|l|}
\hline & Secondary prevention \\
\hline Statins and gemfibrozil & Contraindicated \\
\hline
\end{tabular}

A

5-9

52,53

Ila B

III C

III A

$32-34,36$
$4,5,7,8,13,36,37$

11-13

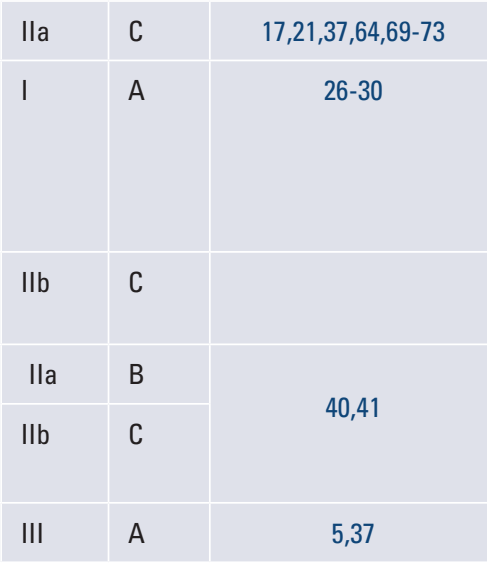

(Continues) 
Table 1. Summary of recommendations with level of evidence (Continued)

\begin{tabular}{|l|l|l|l|l|}
\hline RECOMMENDATIONS & Class & Level & Ref \\
\hline Statins and ezetimibe & $\begin{array}{l}\text { Initial therapy: } \\
\text { If reduction required in LDL-C is }>55 \%\end{array}$ & Ila & C & 10 \\
\hline Second line after potent statins at maximum dose & Ila & B & \\
\hline and failure to achieve the LDL-C goal & $\begin{array}{l}\text { Second line after potent statins at maximum dose } \\
\text { and failure to achieve the LDL-C goal. } \\
\text { Assess and inform the patient about cost-benefit } \\
\text { ratio and make decision together with the patient. }\end{array}$ & Ila & A & $11,12,27,30,33,34$ \\
\hline Therapeutic strategies in case of high or very high risk after maximum tolerable doses of potent statins
\end{tabular}

Increase the statin dose or switch to a more potent statin

\begin{tabular}{|l|c|c|}
\hline Ila & B & $25,26,30$ \\
\hline Ila & B & 10,48 \\
\hline Ila & A & $11,12,29,30,33,34,37,48$ \\
\hline Ila & C & 48 \\
\hline Ila & B & 13,48 \\
\hline I & C & $49-51$ \\
\hline Ilb & C & 40,41 \\
\hline
\end{tabular}

Add ezetimibe

Add PCSK9i, if available and there is an acceptable cost-benefit ratio. Inform and decide together with the patient.

PCSK9i triple therapy (Statins + Ezetimibe + PCSK9i) High risk and failure to achieve the goal with dual therapy. The potential of familial hypercholesterolemia must be assessed.

EPA (4 g/d) for patients with established ASCVD or high risk diabetic patients already on a statin and with TG $>135 \mathrm{mg} / \mathrm{dl}$.

Maintain lipid lowering treatment for an indefinite period of time, at the dose and with the initial regimen, in order to achieve optimum goals based on individual risk estimation, unless unequivocal side effects develop

Fenofibrate $160 \mathrm{mg} / \mathrm{d} /$ High-risk diabetics with at least one RF TG $\geq 200 \mathrm{mg} / \mathrm{dl}$ and HDL-C $\leq$ $40 \mathrm{mg} / \mathrm{dl}$ and LDL-C on target based on risk under statin therapy

\section{Diabetic patients - glucose lowering medications as an option to reduce cardiometabolic risk}

CV risk reduction should be a primordial goal in patients with T2DM, in addition to achieving a proper $\mathrm{HbA} 1 \mathrm{C}$ reduction

It is necessary to discuss the cost-benefit ratio of these novel drugs with the patients before prescribing them

SGLT2i (empagliflozin, canagliflozin, and dapagliflozin) may be prescribed as a first line drug for the purpose of controlling glycemia and reducing CV risk in patients with CVD, HF, CKD, or high to very high CM risk

SGLT2i could be a second line option after stable doses of metformin

In patients with HF and CKD, with or without T2DM, the use of SGLT2I must be considered

GLP-1 (Liraglutide, semaglutide, and dulaglutide) Prior to the use of insulin or together with basal insulin to prevent insulin intensification. As first line therapy in overweight/obese patients with no insulin indication.

GLP-1 (Liraglutide, semaglutide, and dulaglutide) Clinical evidence of ACSVD or high to very

।

I A

I

।

IIa

high cardiometabolic risk, after metformin
A

B

$58-67$

IIa

B

A

58-67

B

62-64

20,65-67

$54-56$

$54-67$

67

\begin{tabular}{l|l|r} 
& Ila & B
\end{tabular}

\section{Hypertension}

The use of a fixed-dose combination is recommended in moderate and high-risk patients as a strategy to improve adherence

\section{Inflammation}

Despite being an important component in pathophysiology and residual risk, there is no recommendation to measure or treat pro-inflammatory risk.

Colchicine could be a useful anti-inflammatory strategy when started early in a post MI scenario and in patients with evidence of stable coronary disease, after treatment with statins, aspirin and ACEI/ARB 
Table 1. Summary of recommendations with level of evidence (Continued)

\begin{tabular}{|c|c|c|c|}
\hline RECOMMENDATIONS & Class & Level & Ref \\
\hline Hs-CRP as a routine approach to lower RCR is not recommended & III & C & \\
\hline \multicolumn{4}{|l|}{ Prothrombotic risk } \\
\hline Aspirin (prior bleeding assessment) in high to very high-risk patients & Ila & A & 21 \\
\hline Aspirin stable CAD and non-cardioembolic ischemic stroke or TIA & 1 & A & $22,23,71$ \\
\hline $\begin{array}{l}\text { Following ACS or after a percutaneous arterial intervention, patients should receive dual } \\
\text { antiplatelet therapy for as long as necessary, depending on the setting and clinical } \\
\text { judgment }\end{array}$ & I & A & 70 \\
\hline $\begin{array}{l}\text { For ACS, rivaroxaban } 2.5 \mathrm{mg} \text { BID may be considered, after discontinuation of parenteral } \\
\text { anticoagulation, in addition to aspirin and clopidogrel, for } 1 \text { year, in the absence of previous } \\
\text { TIA or stroke, and with low risk of bleeding }\end{array}$ & Illb & B & 72 \\
\hline $\begin{array}{l}\text { Patients with atherosclerosis in } \geq 2 \text { vascular beds or two additional risk factors (current } \\
\text { smoking, diabetes, renal insufficiency, HF, or non-lacunar ischemic stroke } \geq 1 \text { month), } \\
\text { rivaroxaban } 2.5 \mathrm{mg} \text { BID may be considered }\end{array}$ & $\mathrm{Ilb}$ & B & 72 \\
\hline Clopidogrel/severe PAD of the lower extremities & IIa & B & 71,72 \\
\hline $\begin{array}{l}\text { Rivaroxaban } 2.5 \mathrm{mg} \text { BID + aspirin } 100 \mathrm{mg} \text { OD } \\
\text { Severe PAD of the lower extremities (low risk of bleeding) }\end{array}$ & Ila & B & 72 \\
\hline Recently vascularized PAD (low risk of bleeding) & 1 & B & 72 \\
\hline $\begin{array}{l}\text { With all antithrombotic and anticoagulant strategies, bleeding is an important risk; } \\
\text { therefore, the net clinical benefit must to be carefully considered in every patient before } \\
\text { prescribing them. }\end{array}$ & I & A & $19-21,72$ \\
\hline
\end{tabular}

\section{Behavioral and Lifestyle-associated Cardiometabolic Risk factors}

Obesity, lack of physical activity, inadequate diet, alcohol abuse, and smoking are all risk factors to consider and assess and to intervene in patients with CMR and in the assessment of RCR

Compliance assessment as an overall risk component must be evaluated in every patient In patients with low or non-adherence, implement strategies that have proven to be helpful, Ila such as using fixed-dose combinations, and polypill based on availability in each country could be an effective choice

\section{General considerations}

Social determinants for CVD or social risk in Latin America must be assessed, since these are basically related to the level of education, income, environmental pollution, models of and access to healthcare services

We strongly recommend the formation of global cardiometabolic risk units to accomplish these goals. This strategy will reduce cardiovascular morbidity-mortality, establishing global cardiometabolic risk protocols that will enable the development of healthy habits, as well as an articulated treatment of all risk factors.

\begin{tabular}{|l|c|c|}
\hline I & A & $24,73-77$ \\
\hline Ila & B & 73 \\
\hline Ila & B & $73-77$ \\
\hline
\end{tabular}

CM risk: cardiometabolic risk; RF: risk factor; RCR: residual cardiometabolic risk; LDL-C: low-density lipoprotein cholesterol; HDL-C: high-density lipoprotein cholesterol; Non HDL-C: non-high density lipoprotein cholesterol; Lp(a): lipoprotein a; ASCVD: atherosclerotic cardiovascular disease; PCSK9i: proprotein convertase subtilisin/kexin type 9 inhibitors; EPA: eicosapentaenoic acid; TG: triglyceride; SGLT2i: sodium/glucose cotransporter 2 inhibitors; GLP-1: glucagon-like peptide 1; ACEI: angiotensin convertase enzyme inhibitors; ARB: angiotensin receptor blocker; Hs-CRP: high sensitivity C-reactive protein; CAD: coronary artery disease; TIA: transient ischemic attack; ACS: acute coronary syndrome; HF: heart failure; PAD: peripheral arterial disease.

implemented to achieve the optimal CM risk reduction (IA). The heightened risk persists as long as all of the factors are not systematically screened and treated. All treatment options must be discussed with the patient and, where appropriate, with his/her family (IA).

\section{Dyslipidemia}

The final goal of lipid-related CM risk is to decrease concentrations of all circulating pro-atherogenic $A p o B$ containing lipoproteins $(I C)^{25}$. Achieving the LDL-C 
risk-stratified target is the primary goal in treating patients with dyslipidemia. Evidence with statin and non-statin therapies, including gastroileal bypass, in different populations with different baseline LDL-C levels and varying risks, has shown a robust association between the reduction of LDL-C and the decline in CM risk ${ }^{26-30}$.

This consensus recommends reducing LDL-C as the primary objective for RRR (IA).

However, it has been observed that, in patients treated with statins, there is a persistent RR secondary to several causes, including:

1) Use of inadequate, low doses of statins.

2) Failure to achieve an optimal LDL-C target.

3) Persistently elevated TgRL concentrations despite adequate LDL-C goal with statin therapy ${ }^{31}$.

$L p(a)$ definitely could be considered a fourth lipid cause of persistent RR, see below in paragraph 1.4 for specific recommendations and management.

Suppl. Table 2 summarizes the results of recent trials that tested different types of drugs as adjuvant therapies with statins in patients with high and very-high CVR. The LDL-C values achieved in the trials with EZT (Improved Reduction of Outcomes: Vytorin Efficacy International Trial (IMPROVE-IT), PCSK9i Further Cardiovascular Outcomes Research with PCSK9i in Subjects with Elevated Risk (FOURIER), and Evaluation of Cardiovascular Outcomes After an Acute Coronary Syndrome During Treatment With Alirocumab (ODYSSEY), are the lowest reported in the history of clinical trials $^{10,11,12}$. LDL-C values as low as $\leq 10 \mathrm{mg} / \mathrm{dl}$ were achieved, accompanied by a significant and safe incremental CVR reduction over and above that observed with statin therapy. These findings suggested that "lower is better, but lowest is best"11-13,32.

There is no known LDL-C threshold below which there is physiological hazard; in fact, many genetic polymorphisms that give rise to the lower LDL-C are protective against the development of atherosclerosis. Meta-analyses show that there is no increased risk for either ischemic or hemorrhagic stroke with the achievement of very low LDL-C. Moreover, the EBBINGHAUS (Evaluating PCSK9i Binding Antibody Influence on Cognitive Health in High Cardiovascular Risk Subjects) trial demonstrated no heightened risk for cognitive impairment even when attaining ultra-low LDL-C of $<10 \mathrm{mg} / \mathrm{dL}^{32,33}$.

In these trials, the ARR was small, which may be due to the fact that most patients were being treated with high statin doses, and their baseline LDL-C was relatively low, as compared to the previous statin monotherapy trials. However, ARR significantly improves as the risk of patients increases ${ }^{34}$.

Therefore, to be cost-effective, it is indispensable to select patients based on their risk and use these therapies in those patients most likely to benefit from them. The patient and, when appropriate, the family, should be included in the decision-making process.

Based on our analysis, to achieve an optimal RRR level, the members of this consensus recommend the following targets for LDL-C (IA):

- Low risk: LDL-C $<115 \mathrm{mg} / \mathrm{dl} / \mathrm{Non}-\mathrm{HDL}-\mathrm{C}<145 \mathrm{mg} / \mathrm{dl}$

- Moderate risk: LDL-C < 100 mg/dl/Non-HDL-C < $130 \mathrm{mg} / \mathrm{dl}$

- High risk: LDL-C $<70 \mathrm{mg} / \mathrm{dl}$ (or at least $50 \%$ reduction)/Non-HDL-C $<100 \mathrm{mg} / \mathrm{dl}$

- Very high risk: LDL-C $<55 \mathrm{mg} / \mathrm{dl}$ (or at least $50 \%$ reduction)/Non-HDL-C $<85 \mathrm{mg} / \mathrm{dl}$

In patients failing to attain these values, a RR associated with insufficiently reduced LDL-C levels will persist. In patients that, despite receiving statins at adequate doses and being at the right goal according to their risk profile, experience a recurrent atherosclerotic cardiovascular event, their LDL-C goal is < $40 \mathrm{mg} / \mathrm{dl}$. (IlbC)

1.1. TgRL, Remnants, and HDL - Recently published evidence, which includes prospective longitudinal cohorts, Mendelian randomization studies, and randomized clinical trials, shows that $\mathrm{TgRL}$ are a component of residual CM risk. Therefore, this panel considers that non-HDL-C, that represent every apoB atherogenic particles including cholesterol remnants, must be assessing. LDL-C overlooks the atherogenic potential of remaining $a p o B$ particles; even lipoprotein (a) also carrying apoB is included in the LDL cholesterol measurement. Indeed, cholesterol remnants as all the TgRL, cause ASCVD just like $\operatorname{LDL}^{35}$. This may be especially important in individuals treated with statins, in obese patients, and in patients with DM or Pre DM in whom cholesterol content in C- LDL is lower than other remnants apoB-containing particles and more cholesterol is transported in TgRL. In those situations, apoB and also non-HDL cholesterol identifies patients with an increased number of cholesterol-containing TG-rich apoB-containing particles, these patients continue to be at high risk of ASCVD events even with C-LDL in target.

That's why we, consider that Non HDL-C should be considered as a secondary goal, once the LDL-C target has been reached ${ }^{36-40}(\mathrm{IA})$, and lowering the non$\mathrm{HDL}-\mathrm{C}$ to risk-stratified levels as a second therapeutic 


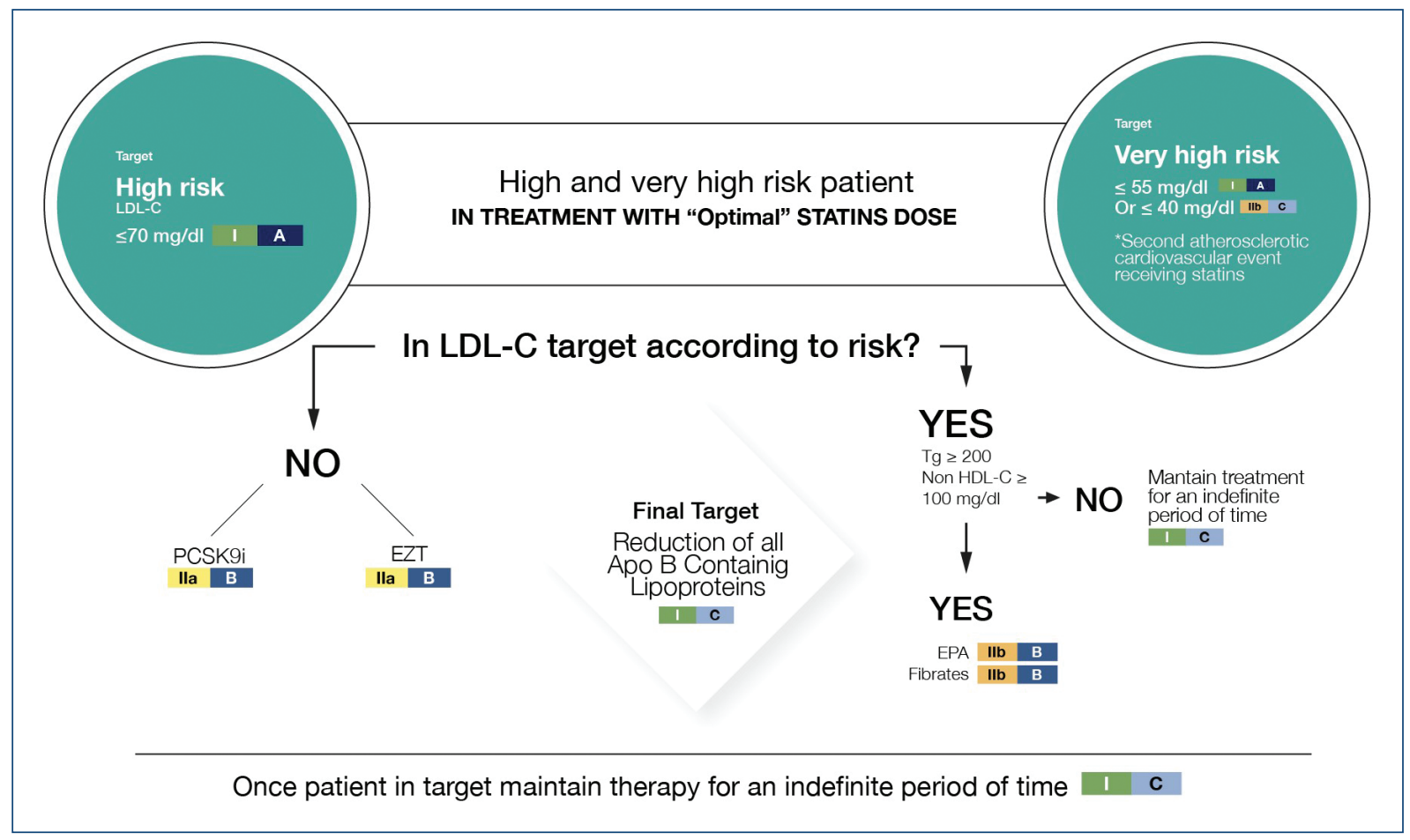

Figure 2. Simplified drug combination algorithm to accomplish therapeutic goals.

objective (IA), since it represents all of the Apo-B-carrying proatherogenic lipoproteins ${ }^{39,40}$.

Apo-B and remnants measurement is expensive and not widely available all Latin American countries. NonHDL-C determination is simple, cost-effective, and has an excellent correlation with TgRL levels, ApoB containing particles and remnants; hence, it can be used as a surrogate marker for $A p o B^{36}$. This consensus recommends a routine calculation of non-HDL-C in all patients (IB) as an Apo B surrogate. In the locations where the measurements of $A p o B$ are possible and it is affordable for the patient, it could be measure after a cost benefit discussion with the patients (IIb).

Epidemiological studies have shown an inverse relationship between low levels of HDL-C and CVR, but it should not be treated since the CCTs that have tested pharmacological strategies to raise levels of HDL-C to the lower the risk $\mathrm{CV}$ events have failed to demonstrate any efficacy ${ }^{41,42}$. This consensus statement does not recommend pharmacological therapy for low HDL-C and agrees that there should not be any HDL-C goals at the present time (IIIA).

1.2. Adjuvant pharmacological therapies to statins to treat $\mathrm{TgRL}$ Achieving the therapeutic goals of all circulating pro-atherogenic ApoB containing lipoproteins $^{25,36}$ is necessary to achieve optimal $\mathrm{CM}$ risk reduction. In many subjects, particularly in those at high and very-high risk, the goals are not achieved with statin monotherapy and, hence, adjuvant therapies should be used. Combination therapy is a common strategy in other conditions such as HBP and T2DM and results in higher rates of therapeutic goal attainment.

A critical analysis based on the levels of evidence available for the various therapeutic classes was conducted, regarding their ability to reduce RR when combined with statins. This consensus panel focused on omega- 3 fatty acids (O3FA) and fibrates as adjunctive therapy to treat residual $\mathrm{CM}$ risk related to high $\mathrm{Tg}$ levels.

FIBRATES: According to available evidence from secondary endpoint analyses, fenofibrate is the only molecule with enough evidence of reducing $\mathrm{CM}$ risk and may be indicated for both primary (IlaB) and secondary prevention (IlbC) $)^{43,44}$. The combination of statins with gemfibrozil is contraindicated (IIIC) since gemfibrozil inhibits their glucuronidation and can lead to myopathy and rhabdomyolysis. Ciprofibrate should not be used due to lack of evidence (IIIC).

O3FA: eicosapentaenoic acid and docosahexaenoic acid (EPA/DHA) have the ability to reduce TG and have been tested in several CCTs with divergent or 
inconclusive results ${ }^{45-47}$. The REDUCE-IT trial, with a highly purified EPA ethyl ester, demonstrated a significant MACE reduction and reduced CV mortality in patients at high and very high risk, treated with statins, with LDL-C at target but $\mathrm{Tg}>150 \mathrm{mg} / \mathrm{dl}^{13}$.

Simplified drug combination algorithm to accomplish therapeutic goals (Fig. 2), the class of drugs with the most conclusive and robust evidence are the statins; consequently, they are indicated as first line agents, using the maximum tolerated dose (IA) (Suppl. Table 3).

Only in the event of a proven statin intolerance and requiring $<20 \%$ LDL-C reduction can we recommend monotherapy with EZT (IIbC).

The drugs recommended for use in combination with statins are: EZT and PCSK9i48 (IlaA).

In patients with an LDL-C > 55\% above the goal, EZT could be in the initial combination (IlbC), or as a second-line adjuvant therapy following high dose potent statins and failing to accomplish the LDL-C goal (IlaB).

In high- or very high-risk patients failing to accomplish the goals after treatment with statin, the following may be recommended:

- Increase doses or switch to a more potent statin (IlaB)

- Add EZT(IlaB)

- Add PCSK9i, if available and cost-effective (IlaA)

- In patients achieving the LDL-C goal, but with a fasting $\mathrm{Tg}>150 \mathrm{mg} / \mathrm{dl}$, (after lifestyle changes for 6 weeks), EPA dose of $4 \mathrm{~g} / \mathrm{d}$ could be prescribed (IlaB)

- In patients who persist with $\mathrm{Tg}>200 \mathrm{mg} / \mathrm{dl}$, fenofibrate could be prescribed at a dose of $160 \mathrm{mg}$ (IlbC)

- Among high risk patients (with established ASCVD or diabetic with multiple risk factors) with TG $>150 \mathrm{mg} /$ $\mathrm{dl}$, icosapent ethyl can be prescribed at a dose of $2.0 \mathrm{~g}$ twice daily (Ila).

1.3. Lipid-lowering treatment duration atherosclerotic disease is a systemic immune inflammatory process that is progressive secondary to exposure of the arterial wall to various risk factors with damage accruing over time.

The 20 year follow-up of "West of Scotland Coronary Prevention Study" showed a 24\% reduction in myocardial infarction (MI), $18 \%$ in coronary events, and a $35 \%$ decrease in HF-related hospital admissions. No reduction was observed in non-CV deaths or stroke ${ }^{49}$. Prospective studies on the impact of discontinuing statins have reported a $33 \%$ increase in CVE and a risk of hospital admissions with $42 \%$ increase in stroke, after 1 year of treatment discontinuation ${ }^{50,51}$.
When combining outcomes data with cost-effectiveness data, we conclude that the use of statins for longterm treatment is efficacious and justified.

This consensus panel recommends the prescription of statins for an indefinite time, at the dose necessary to achieve optimal LDL-C goals based on individual risk (IC), unless unequivocal side effects develop such as myalgia or myopathy, although these are relatively infrequent.

1.4. Lipoprotein (a) $L p(a)$ a unique apo(a) and an apoB-containing lipoprotein particle is one of the most important genetically determined risk factors for CVD. Mendelian randomization studies provide strong support for causality for $L p(a)$ as a causal risk factor for ASCVD, aortic stenosis, and heart failure. Roughly $25 \%$ of the general white population have $L p(a)>30 \mathrm{mg} / \mathrm{dL}$, level associated with high risk. In Latin America it is important to realize that it is demonstrated pronounced differences between ethnic groups (is highest in black people), and differences may depend of standardization of assays, characteristics of population and sample ${ }^{52,53}$.

Based on the evidence available, the consensus agreed that $L p(a)$ is a cause of residual CM risk Many epidemiologic studies confirm that elevated serum levels of $L p(a)$ herald risk for ASCVD (IB).

The object of measuring $L p(a)$ is not to provide treatment, but its assessment to reclassify patients to a higher risk group. Consequently, this consensus panel recommends that whenever the means are available and the cost is justifiable, $\operatorname{Lp}(\mathrm{a})$ should be measured (IlaB).

Clinical conditions in which $L p(a)$ measurement is recommended (IB):

- Early onset or progressive ASCVD with maximum lipid lowering therapy

- Familial hypercholesterolemia

- Early onset of ACVD in family members

- Direct relatives with elevated $L p(a)$.

Measuring $L p(a)$ in patients not included in the above-mentioned cases is not recommended. (IIIC)

2. GLOBAL CM RISK REDUCTION The "Prospective Urban Rural Epidemiology" (PURE) trial ${ }^{24}$ showed that over $70 \%$ of CVD may be attributed to a small number of $\mathrm{CM}$ risk factors: HBP, TgRL, diabetes, pre-diabetes, and abdominal obesity. Hence, this consensus emphasizes the necessity for a comprehensive control of all of these factors for an optimal $\mathrm{CM}$ risk reduction. 
3. GLUCOSE METABOLISM Individuals with T2DM or prediabetes have a higher $\mathrm{CM}$ risk; their primary cause of death is CVD ${ }^{54}$. T2DM medical therapy includes glycemic control to avoid acute metabolic complications and long-term strategies to reduce the risk of micro- and macro-vascular events.

There is a continued need for the development of new antidiabetic drugs and to assess their impact on $\mathrm{CM}$ risk and $\mathrm{CV}$ safety in adequately designed CCT. Historically, clinical trials taught us that the intensive reduction in $\mathrm{HbA}_{1 \mathrm{c}}(<7 \%)$ has a significant impact on microvascular complications, but not on macrovascular events ${ }^{55,56}$. However, the development of newer antiglycemic agents has now provided physicians with the therapeutic means to reduce glycemic indices and reduce risk for macrovascular events, such as $\mathrm{MI}$, ischemic stroke, and CV mortality.

Based on the above discussion, this consensus recommends that $\mathrm{CV}$ risk reduction should be a primordial goal in patients with T2DM, in addition to achieving a proper $\mathrm{HbA1c}$ reduction (IA).

3.1. SGLT2 inhibitors Sodium-glucose cotransporter 2 inhibitors (SGLT2i): dapagliflozin, empagliflozin, and canagliflozin, induce glucosuria by inhibiting the uptake of glucose along the proximal tubule, reduce serum glucose levels, promote diuresis and sodium elimination, lower BP, and serum uric acid and are associated with weight loss. Other effects include lowering intraglomerular pressure and proteinuria, preventing tubulo-interstitial and glomerular injury, inhibiting the sodium-proton exchanger, and increasing hematocrit, serum beta-hydroxybutyrate, and angiotensin $1-7^{57}$. These medications have a low risk for hypoglycemia.

These drugs have been tested in several clinical trials (Suppl. Table 4) and have demonstrated consistent cardio-renal-vascular protection, regardless of the diagnosis or not of T2DM ${ }^{58-67}$.

Based on the results of these clinical trials, this consensus panel recommends:

1) In patients with T2DM and established CVD, HF, CKD or high to very high CM risk, SGLT2i may be prescribed as a first-line drug for the purpose of controlling glycaemia and reducing CV risk (IB).

2) SGLT2i may be used as a second line option after metformin. (IlaB)

3) In patients with HF and/or CKD, with or without T2DM, the use of SGLT2I should be considered (IA).

4) Regard chronic kidney disease emerging evidence derived from RCTs and meta-analyses demonstrate a cardio-protective and nephro-protective effects of
Table 2. Recommendations for managing lifestyle changes

\begin{tabular}{|c|c|c|}
\hline Risk factor & Goal & Type of therapy \\
\hline Obesity & $\begin{array}{l}\text { BMI }<25 \\
\text { WAIST-HIP RATIO } \\
\text { Males: }<0.90 \\
\text { Females: }<0.84\end{array}$ & $\begin{array}{l}\text { Indicate: } \\
\text { - Lifestyle changes } \\
\text { - Diet } 800-1500 \mathrm{Kcal} / \\
\text { day } \\
\text { - Exercise 200-300 min/ } \\
\text { week } \\
\text { - Metabolic surgery in } \\
\text { patients with a BMI } \\
>35 \text { and two } \\
\text { comorbidities or a } \\
\text { BMI > 40 } \\
\text { Potential } \\
\text { recommendation: } \\
\text { - Orlistat }\end{array}$ \\
\hline Smoking & Smoking cessation & $\begin{array}{l}\text { Recommended: } \\
\text { - Psychotherapy } \\
\text { - Chewing gum } \\
\text { - Drug therapy } \\
\text { - Bupropion, } \\
\text { Varenicline } \\
\text { Tobacco in any form not } \\
\text { allowed (Vaping, inhaling } \\
\text { chewing, etc.) }\end{array}$ \\
\hline HBP & $<140 / 90$ & $\begin{array}{l}\text { Indicated: } \\
\text { - Lifestyle changes } \\
\text { - Salt intake } 7.5-12 \mathrm{~g} / \\
\text { day } \\
\text { - Physical activity } \\
200-300 \text { min/week } \\
\text { with } 40 \% \text { strength }\end{array}$ \\
\hline Dysglycemia & Hba1c $<5.7$ & $\begin{array}{l}\text { Recommended } \\
\text { - Fiber-rich diet and } \\
\text { reduced intake of } \\
\text { refined carbohydrates } \\
\text { - Physical activity at } \\
\text { least } 150 \text { min/week } \\
\text { with } 40 \% \text { strength }\end{array}$ \\
\hline
\end{tabular}

SGLT2i. We recommend their use in patients with baseline eGFR up to $30 \mathrm{~mL} / \mathrm{min} / 1.73 \mathrm{~m}^{2}$.

3.2. GLP-1 receptor agonists Glucagon-like peptide-1 receptor agonists are the only injectable non-insulin therapy for controlling T2DM, with high glucose-lowering power (with low risk of hypoglyce$\mathrm{mia}$ ), and significant weight loss ${ }^{20}$.

Liraglutide, semaglutide, and dulaglutide have been proven to reduce the risk of MACE (Suppl. Table 4), whereas lixisenatide and extended-release exenatide have a neutral effect ${ }^{65-67}$.

This consensus recommends GLP-1 receptor agonists (liraglutide, semaglutide, and dulaglutide) as a treatment option in patients with evidence of ASCVD who are at high risk after metformin, or before the use of insulin, or together with basal insulin to prevent insulin intensification; this could be a parenteral first line therapy in 
overweight patients with no insulin indication (IlaB). Availability of and accessibility to these medications should be considered and it is necessary to discuss the cost-benefit ratio with the patients before prescribing (IA).

\section{Hypertension}

$\mathrm{HBP}$ is the risk factor with the highest attributable risk; $\mathrm{BP}$ control is critical in reducing $\mathrm{CM}$ risk. A detailed discussion about the BP goals and treatment regimens is beyond the scope of this paper (refer to the IASC Statement) ${ }^{68}$.

Pharmacological therapy should start at $\mathrm{BP} \geq$ $140 / 90 \mathrm{~mm} \mathrm{Hg}$; the recommended goals should be < $130 / 85 \mathrm{~mm} \mathrm{Hg}$. The recommended drug classes are: ACE inhibitors/angiotensin receptor blockers, thiazide diuretics, calcium antagonists, and beta-blockers. Mineralocorticoid receptor blockers may be prescribed in difficult to manage cases or refractory HBP. The use of fixed dose combination therapy is recommended in moderate- and high-risk patients as a strategy to improve BP control and long-term adherence (IA).

\section{Inflammation}

Plays a pivotal role in atherogenesis, acute plaque rupture, and ASCVD-related events ${ }^{9}$. Therefore, inflammation is a significant factor to consider as a cause of RR.

Three pharmacological strategies have been tested in trying to show that, by selectively and independently reducing vascular inflammation, a decline in $R R$ is achieved.

a) Canakinumab: The CANTOS trial reported a significant benefit; it is a drug with an extremely high cost and hence it is not recommended for the treatment of patients with an elevated RCR (IIIC) ${ }^{14}$. It is also not approved for this indication.

b) Colchicine: An affordable anti-inflammatory drug has been tested targeting inflammation to reduce CV risk $^{15-18}$. Colchicine Cardiovascular Outcomes Trial (COLCOT) demonstrated a beneficial impact of lowdose colchicine $(0.5 \mathrm{~g} / \mathrm{d})$ in the post-Ml setting. A recent analysis shows that early initiation of colchicine within the first 3 days after $\mathrm{Ml}$ is associated with a greater reduction of the primary endpoint ${ }^{15}$.

In LODOCO 2 (a trial which used low doses of colchicine), the primary end point was reduced significant$\mid y^{17}$. Low-dose therapy was not associated with any serious adverse effects.
Results of the Colchicine in Patients with Acute Coronary Syndrome (COPS) trial showed that colchicine does not improve CV outcomes in patients with ACS. The differences with the previous results could be in part due to the size of the cohort studied ${ }^{18}$.

5.3. Methotrexate: The Cardiovascular Inflammation Reduction Trial (CIRT) observed that, at low doses, it failed to reduce the risk of $\mathrm{CV}$ events ${ }^{69}$.

The major implications of these findings are that it may be possible to reduce the risk of $\mathrm{CV}$ events in patients with stable coronary disease by targeting inflammation. This consensus recommends that:

a) Colchicine could be a useful anti-inflammatory strategy if started early in a post Ml scenario and in patients with evidence of stable coronary disease, after treatment with statins, aspirin, and ACEI/ARB (IllbB).

b) This consensus does not recommend assessing inflammation hs-CRP as a routine approach to the lower RCR (IIIA).

\section{Prothrombotic status}

Effective and safe anti-thrombotic therapy using antiplatelet ${ }^{21,22}$ and anticoagulation drugs $\mathrm{s}^{70-72}$ is essential to reducing RCR. This consensus recommends the use of an antithrombotic therapy, depending on the drug type and patient's clinical scenario:

a) In patients with high or very-high cardiovascular risk, assess the risk of bleeding and consider aspirin therapy (IlaA).

b) All patients with stable coronary disease and non-cardioembolic ischemic stroke or TIA should receive aspirin (75-81 mg) (IA).

c) Following ACS or after a percutaneous arterial intervention, patients should receive dual antiplatelet therapy for as long as necessary, depending on the setting and clinical judgment $(\mathrm{IA})^{21,22}$.

d) For ACS, rivaroxaban $2.5 \mathrm{mg}$ BID may be considered, in addition to aspirin and clopidogrel, for 1 year, in patients with an elevated risk of ischemia, in the absence of the previous TIA or stroke, and with low risk of bleeding (IlbB) ${ }^{23,72}$.

e) In patients with severe lower extremity PAD, clopidogrel may be considered (IlaB).

f) In patients with severe PAD of the lower extremities and with low risk of bleeding, the combination of rivaroxaban $2.5 \mathrm{mg} \mathrm{BID}$ plus aspirin $100 \mathrm{mg} /$ day could be considered $(\mathrm{IlaB})^{71}$.

g) In patients with recently vascularized PAD and low risk of bleeding, the combination of rivaroxaban 
$2.5 \mathrm{mg} \mathrm{BID}$ plus aspirin $100 \mathrm{mg} /$ day is recommended $(\mathrm{IB})^{70}$.

\section{Behavioral And Lifestyle-Associated CM Risk Factors}

Obesity, physical inactivity, inadequate diet, alcohol abuse, and smoking are enhancing risk factors to consider for evaluation in patients with $\mathrm{CM}$ risk and in the assessment of RCR $(\mathrm{IA})^{24,73-77}$.

Poor compliance and lack of long-term adherence are behavioral attitudes that are additional risk factor in patients with $\mathrm{CM}$ risk. Depression and anxiety could increase the lack of adherence to drugs and lifestyle modifications. Therefore, it is mandatory to inquire about poor adherence as an overall risk component, usually associated with the number of pills prescribed. This consensus recommends the implementation of strategies to improve compliance and hence reduce risk, such as using fixed-dose combinations in patients prescribed individual components, based on availability in each country (IA).

Table 2 summarizes the recommendations for these risk factors in all patients.

To minimize the incidence of CVD in the population, as well as to reduce RCR, physicians must be aware of the importance of risk factors and lifestyles, so that they may routinely and systematically explain them to the patient, their family, including children and adolescents, at each visit.

What has been described as the social determinants for CVD or social risk in Latin America must be assessed, since these are basically related to the level of education, income, and access to health-care services (IA). Finally, this consensus wants to underscore the need to evaluate and treat $\mathrm{CM}$ risk in a comprehensive and integrated way to achieve an optimal control of all risks. In this respect, we strongly recommend that global CM risk units be formed to accomplish this goal. This strategy will reduce cardiovascular morbidity-mortality; establishing global CM risk prevention protocols that will enable the development of healthy habits, as well as an articulated treatment of all risk factors (IA).

\section{Acknowledgments}

The authors would like to thank Lic. Ximena Sánchez Aquique for their logistic support during the development of the manuscript, and Andrea Niño for the unevaluable assistance in final spelling and grammar of the manuscript.

\section{Funding}

Tecnofarma S.A. de C.V. A private Laboratories contributed with an unrestrictive grant used exclusively for the logistical expenses of the research meeting.

\section{Conflicts of interest}

On behalf of all Co-Authors, I Carlos I. Ponte-Negretti the corresponding author do have the responsibility for the submission. All authors were requested to disclose any actual or potential conflict of interest including any financial, personal or other relationships with other people or organizations within 3 years of beginning the submitted work that could inappropriately influence, or be perceived to influence, their work.

\section{Ethical disclosures}

Protection of human and animal subjects. The authors declare that no experiments were performed on humans or animals for this study.

Confidentiality of data. The authors declare that no patient data appear in this article.

Right to privacy and informed consent. The authors declare that no patient data appear in this article.

\section{SUPPLEMENTARY DATA}

Supplementary data are available at https://doi. org/10.24875/ACM.21000005. These data are provided by the corresponding author and published online for the benefit of the reader. The contents of supplementary data are the sole responsibility of the authors.

\section{References}

1. GBD 2017 Causes of Death Collaborators. Global, regional, and national age-sex-specific mortality for 282 causes of death in 195 countries and territories, 1980-2017: a systematic analysis for the global burden of disease study 2017. Lancet. 2018;392:1736-88.

2. Januzzi JL Jr., Ahmad T, Binder LG, Hucker WJ, Kumbhani DJ, Maddox TM. et al. 2019 Methodology for creating expert consensus decision pathways: a report of the American college of cardiology. J Am Coll Cardiol. 2019;74:1138-50.

3. Crawford M, Wright G. Delphi method. In: Wiley StatsRef: statistics Reference Online. United States: Wiley; 2016. p. 1-6.

4. Fruchart JC, Davignon J, Hermans MP, Al-Rubeaan K, Amarenco P, Assmann G, et al. Residual risk reduction initiative (R3i). Residual macrovascular risk in 2013: what have we learned? Cardiovasc Diabetol. 2014;13:26.

5. Averna M, Stroes E, Alterations Beyond LDL Expert Working Group. How to assess and manage cardiovascular risk associated with lipid alterations beyond LDL. Atheroscler Suppl. 2017;26:16-24.

6. Collins R, Reith C, Emberson J, Armitage J, Baigent C, Blackwell L, et al. Interpretation of the evidence for the efficacy and safety of statin therapy. Lancet. 2016:388:2532-61.

7. Ganda O, Bhatt D, Mason P, Miller M, Boden W. Unmet need for adjunctive dyslipidemia therapy in hypertriglyceridemia management. JACC. 2018;72:330-43 
8. Ferrari R, Catapano AL. Residual cardiovascular risk. Eur Heart J Suppl. 2016;18:C2-12

9. Patel KV, Pandey A, de Lemos JA. Conceptual framework for addressing residual atherosclerotic cardiovascular disease risk in the era of precision medicine. Circulation. 2018;137:2551-3.

10. Cannon CP, Blazing MA, Giugliano RP, McCagg A, White JA, Theroux $P$, et al, IMPROVE-IT Investigators. Ezetimibe added to statin therapy after acute coronary syndromes. N Engl J Med. 2015:372:2387-97.

11. Sabatine MS, Giugliano RP, Keech AC, Honarpour N, Wiviott SD, Murphy SA, el al, FOURIER Steering Committee and Investigators. Evolocumab and clinical outcomes in patients with cardiovascular disease. N Engl J Med. 2017;376:1713-22.

12. Schwartz GG, Steg PG, Szarek M, Bhatt DL, Bittner VA, Diaz R, et al, ODYSSEY OUTCOMES Committees and Investigators. Alirocumab and cardiovascular outcomes after acute coronary syndrome. N Engl J Med. 2018;379:2097-107.

13. Bhatt DL, Steg PG, Miller M, Brinton EA, Jacobson TA, Ketchum SB, et al, CM REDUCE-IT Investigators. Cardiovascular risk reduction with icosapent ethyl for hypertriglyceridemia. N Engl J Med. 2019;380:11-22.

14. Ridker PM, Everett BM, Thuren T, MacFadyen JG, Chang WH, Ballantyne C, et al, CANTOS Trial Group. Antiinflammatory therapy with canakinumab for atherosclerotic disease. N Engl J Med. 2017;377:1119-31.

15. Bouabdallaoui N, Tardif JC, Waters DD, Pinto FJ, Maggioni AP, Diaz R, et al. Time-to-treatment initiation of colchicine and cardiovascular outcomes after myocardial infarction in the colchicine cardiovascular outcomes trial (COLCOT). Eur Heart J. 2020;41:4092-9.

16. Tardif JC, Kouz S, Waters DD, Bertrand OF, Diaz R, Maggioni AP, et al. Efficacy and safety of low-dose colchicine after myocardial infarction. N Engl J Med. 2019;381:2497-505

17. Nidorf SM, Fiolet AT, Mosterd A, Eikelboom JW, Schut A, Opstal TS, et al, $\mathrm{LoDoCO}_{2}$ Trial Investigators. Colchicine in patients with chronic coronary disease. N Engl J Med. 2020;383:1838-47.

18. Tong DC, Quinn S, Nasis A, Hiew C, Roberts-Thomson P, Adams H, et al. Colchicine in patients with acute coronary syndrome: the Australian COPS randomized clinical trial. Circulation. 2020;142:1890-900

19. Zou CY, Liu XK, Sang YQ, Wang B, Liang J. Effects of SGLT2 inhibitors on cardiovascular outcomes and mortality in Type 2 diabetes: a meta-analysis. Medicine (Baltimore). 2019;98:e18245.

20. Sinha B, Ghosal S. Meta-analyses of the effects of DPP-4 inhibitors, SGLT2 inhibitors and GLP1 receptor analogues on cardiovascular death, myocardial infarction, stroke and hospitalization for heart failure. Diabetes Res Clin Pract. 2019;150:8-16.

21. Bittl JA, Baber U, Bradley SM, Wijeysundera DN. Duration of dual antiplatelet therapy: a systematic review for the 2016 ACC/AHA guideline focused update on duration of dual antiplatelet therapy in patients with coronary artery disease: a report of the American college of cardiology/ American heart association task force on clinical practice guidelines. J Am Coll Cardiol. 2016;68:1116-39.

22. Bonaca MP, Bhatt DL, Cohen M, Steg PG, Storey RF, Jensen EC, et al, PEGASUS-TIMI 54 Steering Committee and Investigators. Long-term use of ticagrelor in patients with prior myocardial infarction. N Engl J Med. 2015:372:1791-800.

23. Eikelboom JW, Connolly SJ, Bosch J, Dagenais GR, Hart RG, Shestakovska O, et al, COMPASS Investigators. Rivaroxaban with or without aspirin in stable cardiovascular disease. N Engl J Med. 2017:377:1319-30.

24. Yusuf S, Joseph P, Rangarajan S, Islam S, Mente A, Hystad P, et al. Modifiable risk factors, cardiovascular disease, and mortality in 155722 individuals from 21 high-income, middle-income, and low-income countries (PURE): a prospective cohort study. Lancet. 2020;395:795-808.

25. Rana JS, Liu JY, Moffet HH, Boklage SH, Khan I, Karter AJ. Risk of incident atherosclerotic cardiovascular disease events by achieved atherogenic lipid levels among 62,428 statin-treated individuals with diabetes mellitus. Am J Cardiol. 2018;122:762-7.

26. Cholesterol Treatment Trialists' (CTT) Collaboration, Baigent C. Efficacy and safety of more intensive lowering of LDL cholesterol: a meta-analysis of data from 170,000 participants in 26 randomised trials. Lancet. 2010;376:1670-81.

27. Sabatine MS, Wiviott SD, Im K, Murphy SA, Giugliano RP. Efficacy and safety of further lowering of low-density lipoprotein cholesterol in patients starting with very low levels: a meta-analysis. JAMA Cardiol. 2018;3:823-8.

28. Ference BA, Ginsberg HN, Graham I, Ray KK, Packard CJ, Bruckert E, et al. Low-density lipoproteins cause atherosclerotic cardiovascular disease. 1. Evidence from genetic, epidemiologic, and clinical studies. A consensus statement from the European atherosclerosis society consensus panel. Eur Heart J. 2017;38:2459-72.

29. Mundi S, Massaro M, Scoditti E, Carluccio MA, van Hinsbergh VW Iruela-Arispe ML, et al. Endothelial permeability, LDL deposition, and cardiovascular risk factors-a review. Cardiovasc Res. 2018;114:35-52.

30. Silverman MG, Ference BA, Im K, Wiviott SD, Giugliano RP, Grundy SM et al. Association between lowering LDL-C and cardiovascular risk reduction among different therapeutic interventions: a systematic review and meta-analysis. JAMA. 2016;316:1289-97.
31. Nordestgaard BG. Triglyceride-rich lipoproteins and atherosclerotic cardiovascular disease: new insights from epidemiology, genetics, and biology. Circ Res. 2016;118:547-63.

32. Masana L, Girona J, lbarretxe D, Rodríguez-Calvo $R$, Rosales $R$ Vallvé JC, et al. Clinical and pathophysiological evidence supporting the safety of extremely low LDL levels-The zero-LDL hypothesis. J Clin Lipidol. 2018;12:292-9.e3.

33. Giugliano RP, Mach F, Zavitz K, Kurtz C, Im K, Kanevsky E, EBBINGHAUS Investigators. Cognitive function in a randomized trial of evolocumab. N Engl J Med. 2017;377:633-43.

34. Giugliano RP, Pedersen TR, Park JG, De Ferrari GM, Gaciong ZA, Ceska R, et al, FOURIER Investigators. Clinical efficacy and safety of achieving very low LDL-cholesterol concentrations with the PCSK9 inhibitor evolocumab: a prespecified secondary analysis of the FOURIER trial. Lancet. 2017:390:1962-71.

35. Ditlev C, Johannesen L, Bødtker Mortensen M, Langsted A, Nordestgaard BG. Apolipoprotein $B$ and non-HDL cholesterol better reflect residual risk than LDL cholesterol in statin-treated patients. J Am Coll Cardiol. 2021;77:1439-50.

36. Ballantyne CM, Bertolami M, Hernandez Garcia HR, Nul D, Stein EA, Theroux $\mathrm{P}$, et al. Achieving LDL cholesterol, non-HDL cholesterol, and apolipoprotein B target levels in high-risk patients: measuring effective reductions in cholesterol using rosuvastatin therapy (MERCURY) II. Am Heart J. 2006;151:975.e1-9.

37. Perrone V, Sangiorgi D, Buda S, Degli Esposti L. Residual cardiovascular risk in patients who received lipid-lowering treatment in a real-life setting: retrospective study. Clinicoecon Outcomes Res. 2016;8:649-55.

38. Johansen CT, Hegele RA. Using mendelian randomization to determine causative factors in cardiovascular disease. J Intern Med. 2013:273:44-7.

39. Ponte-Negretti Cl, Isea-Perez JE, Lorenzatti AJ, Lopez-Jaramillo P, Wyss-Q FS, Pintó X, et al. Atherogenic dyslipidemia in Latin America: prevalence, causes and treatment: expert's position paper made by the Latin American academy for the study of lipids (ALALIP) endorsed by the inter-American society of cardiology (IASC), the South American society of cardiology (SSC), the Pan-American college of endothelium (PACE), and the international atherosclerosis society (IAS). Int $\mathrm{J}$ Cardiol. 2017;243:516-22.

40. Villines TC, Stanek EJ, Devine PJ, Turco M, Miller M, Weissman NJ, et al. The ARBITER 6-HALTS trial (Arterial biology for the investigation of the treatment effects of reducing cholesterol 6-HDL and LDL Treatment Strategies in Atherosclerosis): final results and the impact of medication adherence, dose, and treatment duration. J Am Coll Cardiol. 2010;55:2721-6.

41. AIM-HIGH Investigators, Boden WE, Probstfield JL, Anderson T, Chaitman BR, Desvignes-Nickens P, Koprowicz K, et al. Niacin in patients with low HDL cholesterol levels receiving intensive statin therapy. N Engl J Med. 2011;365:2255-67.

42. ACCORD Study Group, Cushman WC, Evans GW, Byington RP, Goff DC Jr., Grimm RH Jr., Cutler JA, et al. Effects of intensive blood-pressure control in Type 2 diabetes mellitus. N Engl J Med. 2010;362:1575-85

43. Scott R, O'Brien R, Fulcher G, Pardy C, D'Emden M, Tse D, et al. Fenofibrate Intervention and Event Lowering in Diabetes (FIELD) Study Investigators. Effects of fenofibrate treatment on cardiovascular disease risk in 9,795 individuals with Type 2 diabetes and various components of the metabolic syndrome: the fenofibrate intervention and event lowering in diabetes (FIELD) study. Diabetes Care. 2009;32:493-8.

44. ORIGIN Trial Investigators, Bosch J, Gerstein HC, Dagenais GR, Díaz R, Dyal $L$, Jung $\mathrm{H}$, et al. N-3 fatty acids and cardiovascular outcomes in patients with dysglycemia. N Engl J Med. 2012;367:309-18.

45. The ASCEND Study Collaborative Group. Effects of $n-3$ fatty acid supplements in diabetes mellitus. N Engl J Med 2018;379:1540-50.

46. Aung T, Halsey J, Kromhout D, Gerstein HC, Marchioli R, Tavazzi L, et al, Omega-3 Treatment Trialists' Collaboration. Associations of Omega-3 fatty acid supplement use with cardiovascular disease risks: meta-analysis of 10 trials involving 77917 individuals. JAMA Cardiol. 2018;3:225-34.

47. Ponte-N C, Machado HL. Lipidología y prevención cardiovascular La era de las combinaciones llegaron para quedarse. JACC Spanish Ed 2020;1:120-3

48. Ford I, Murray H, McCowan C, Packard CJ. Long-term safety and efficacy of lowering low-density lipoprotein cholesterol with statin therapy: 20-year follow-up of west of Scotland coronary prevention study. Circulation. 2016;133:1073-80.

49. Thanassoulis G, Sniderman AD, Pencina MJ. A long-term benefit approach vs standard risk-based approaches for statin eligibility in primary prevention. JAMA Cardiol. 2018;3:1090-5.

50. Willeit P, Ridker PM, Nestel PJ, Simes J, Tonkin AM, Pedersen TR, et al. Baseline and on-statin treatment lipoprotein(a) levels for prediction of cardiovascular events: individual patient-data meta-analysis of statin outcome trials. Lancet. 2018;392:1311-20.

51. Verbeek R, Hoogeveen RM, Langsted A, Stiekema LC, Verweij SL, Hovingh GK, et al. Cardiovascular disease risk associated with elevated lipoprotein(a) attenuates at low low-density lipoprotein cholesterol levels in a primary prevention setting. Eur Heart J. 2018:39:2589-96. 
52. Bertoluci MC, Rocha VZ. Cardiovascular risk assessment in patients with diabetes. Diabetol Metab Syndr. 2017;9:25.

53. Low Wang CC, Everett BM, Burman KD, Wilson PW. Cardiovascular safety trials for all new diabetes mellitus drugs? Circulation. 2019;139:1741-3.

54. Ray KK, Seshasai SR, Wijesuriya S, Sivakumaran R, Nethercott S, Preiss D, et al. Effect of intensive control of glucose on cardiovascular outcomes and death in patients with diabetes mellitus: a meta-analysis of randomised controlled trials. Lancet. 2017;24:44-51.

55. Verma S, McMurray JJ. SGLT2 inhibitors and mechanisms of cardiovascular benefit: a state-of-the-art review. Diabetologia. 2018:61:2108-17.

56. Zinman B, Wanner C, Lachin JM, Fitchett D, Bluhmki E, Hantel S, et al, The EMPA-REG OUTCOME Investigators. Empagliflozin, cardiovascular outcomes, and mortality in Type 2 diabetes. N Engl J Med. 2015;373: 2117-28.

57. Neal B, Perkovic V, Mahaffey KW, de Zeeuw D, Fulcher G, Erondu N et al, CANVAS Program Collaborative Group. Canagliflozin and cardiovascular and renal events in Type 2 diabetes. N Engl J Med. 2017;377: 644-57.

58. Wiviott SD, Raz I, Bonaca MP, Mosenzon O, Kato ET, Cahn A, et al, MS DECLARE-TIMI 58 Investigators. Dapagliflozin and cardiovascular outcomes in Type 2 diabetes. N Engl J Med. 2019;380:347-57.

59. Kluger AY, Tecson KM, Barbin CM, Lee AY, Lerma EV, Rosol ZP, et al. Cardiorenal outcomes in the CANVAS, DECLARE-TIMI 58, and EMPA-REG OUTCOME trials: a systematic review. Rev Cardiovasc Med. 2018;19:41-9.

60. Packer M, Anker SD, Butler J, Filippatos G, Pocock SJ, Carson P, et al, EMPEROR-Reduced Trial Investigators. Cardiovascular and renal outcomes with empagliflozin in heart failure. $\mathrm{N}$ Engl $\mathrm{J}$ Med. 2020;383:1413-24.

61. McMurray JJ, DeMets DL, Inzucchi SE, Køber L, Kosiborod MN, Langkilde AM, et al, DAPA-HF Committees and Investigators. A trial to evaluate the effect of the sodium-glucose co-transporter 2 inhibitor dapagliflozin on morbidity and mortality in patients with heart failure and reduced left ventricular ejection fraction (DAPA-HF). Eur J Heart Fail. 2019;21: 665-75.

62. Heerspink HJ, Stefánsson BV, Correa-Rotter R, Chertow GM, Greene T, Hou FF, et al, DAPA-CKD Trial Committees and Investigators. Dapagliflozin in patients with chronic kidney disease. $N$ Engl J Med. 2020;383:1436-46.

63. Marso SP, Daniels GH, Brown-Frandsen K, Kristensen P, Mann JF Nauck MA, et al, LEADER Steering Committee, LEADER Trial Investigators. Liraglutide and cardiovascular outcomes in Type 2 diabetes. N Eng J Med. 2016;375:311-22.

64. Marso SP, Bain SC, Consoli A, Eliaschewitz FG, Jódar E, Leiter LA et al, SUSTAIN-6 Investigators. Semaglutide and cardiovascular outcomes in patients with Type 2 diabetes. N Engl J Med. 2016;375:1834-44.
65. Gerstein HC, Colhoun HM, Dagenais GR, Diaz R, Lakshmanan M, Pais $P$, et al, REWIND Investigators. Dulaglutide and cardiovascular outcomes in Type 2 diabetes (REWIND): a double-blind, randomised placebo-controlled trial. Lancet. 2019:394:121-30.

66. Wyss F, Coca A, Lopez-Jaramillo P, Ponte-Negretti C. The Task Force for the Management of Arterial Hypertension of the Interamerican Society of Cardiology (IASC), Reviewers from the European Society of Hypertension (ESH), Latin-American Society of Hypertension (LASH), and the Spanish Society of Cardiology (SSC). Position statement of the Interamerican society of cardiology (IASC) on the current guidelines for the prevention, diagnosis and treatment of arterial hypertension 2017-2020. Int J Cardiol Hypertens. 2020;6:100041.

67. Ridker PM, Everett BM, Pradhan A, MacFadyen JG, Solomon DH, Zaharris E, CIRT Investigators. Low-dose methotrexate for the prevention of atherosclerotic events. N Engl J Med 2019;380:752-76.

68. Capell WH, Bonaca MP, Nehler MR, Chen E, Kittelson JM, Anand SS, et al. Rationale and design for the vascular outcomes study of ASA along with rivaroxaban in endovascular or surgical limb revascularization for peripheral artery disease (VOYAGER PAD). Am Heart J. 2018;199:83-91.

69. Anand SS, Bosch J, Eikelboom JW, Connolly SJ, Diaz R, Widimsky P, et al, COMPASS Investigators. Rivaroxaban with or without aspirin in patients with stable peripheral or carotid artery disease: an international, randomised, double-blind, placebo-controlled trial. Lancet. 2018;391:219-29.

70. Mega JL, Braunwald E, Wiviott SD, Bassand JP, Bhatt DL, Bode C, et al, ATLAS ACS 2-TIMI 51 Investigators. Rivaroxaban in patients with a recent acute coronary syndrome. N Engl J Med. 2012;366:9-19.

71. Nocon M, Hiemann T, Müller-Riemenschneider F, Thalau F, Roll S, Willich SN. Association of physical activity with all-cause and cardiovascular mortality: a systematic review and meta-analysis. Eur J Cardiovasc Prev Rehabil. 2008;15:239-46.

72. American Heart Association. Council on Lifestyle and Cardiometabolic Health. Available from: https://www.professional.heart.org/professional/ MembershipCouncils/ScientificCouncils/UCM_322856_Council-on-Lifestyle-and-Cardiometabolic-Health.jsp. [Last accessed on 2018 Sep ${ }^{19}$

73. Mente A, de Koning L, Shannon HS, Anand SS. A systematic review of the evidence supporting a causal link between dietary factors and coronary heart disease. Arch Intern Med. 2009;169:659-69.

74. Barua RS, Rigotti NA, Benowitz NL, Cummings KM, Jazayeri MA, Morris PB, et al. 2018 ACC expert consensus decision pathway on tobacco cessation treatment: a report of the American college of cardiology task force on clinical expert consensus documents. J Am Coll Cardiol. 2018;72:3332-65.

75. Sosa-Liprandi Á, Sosa Liprandi MI, Alexánderson E, Avezum Á, Lanas F, López-Jaramillo JP, et al. Clinical impact of the polypill for cardiovascular prevention in Latin America: a consensus statement of the inter-American society of cardiology. Glob Heart. 2019;14:3-16.e1. 